\section{Fatal pneumonia associated with two viruses in a child with lymphoblastic leukaemia}

Infections with more than one virus may cause morbidity and mortality in children with acute lymphoblastic leukaemia, ${ }^{1}$ and multiple isolates of viruses have been found in the upper respiratory tract of such children. ${ }^{2}$ The role of Herpesvirus hominis is not always clear because carriers are common, but this virus may have been an important contributory factor in the death of the patient described here.

\section{Case report}

A boy aged 3 years 9 months presented with standard-risk acute lymphoblastic leukaemia after a three-week history of lethargy, knee pain, and pallor. He was treated according to the then current Medical Research Council trial schedule UKALL V and achieved satisfactory remission. Apart from occasional upper respiratory tract infections he remained well for 10 months with maintenance doses of daily mercaptopurine and weekly methotrexate. He was then readmitted with a week's history of coughing, malaise, and fever.

A chest radiograph showed patchy consolidation in the right lung. His leucocyte count was $1.4 \times 10^{\circ} / 1\left(1400 / \mathrm{mm}^{3}\right.$; neutrophils $70 \%$, lymphocytes $20 \%$ ). His condition deteriorated over the next 13 days despite various antibiotics, and no appreciable rise was detected in viral complementfixation test titres (including herpes simplex, measles, and cytomegalovirus) up to 21 days after the onset of symptoms. Open-lung biopsy showed a few giant cells with intranuclear inclusion bodies scattered over areas of chronic interstitial inflammation, fibrosis, necrosis, and oedema with hyaline membranes and epithelial overgrowth in the alveolae, suggesting acute viral pneumonia (figure). Pneumocystis carinii was not evident on appropriate staining. Measles antigen was detected in the lung smears by the fluorescent antibody technique, and the virus was subsequently grown in the urine.

Despite assisted ventilation the child died five days later with irreversible respiratory failure. Limited necropsy was performed through the thoracotomy incision, and histological examination confirmed the biopsy finding. In addition, however, cell culture of lung tissue grew both measlesvirus on primary baboon kidney and $H$ hominis on human embryonic lung fibroblasts (MRC 5). The viruses were identified by neutralisation tests. He had never been vaccinated against measles but had been in contact with it six months before his death and been given $750 \mathrm{mg}$ of broad-spectrum gammaglobulin. There was no known second contact with measles in the month before the onset of his terminal illness.

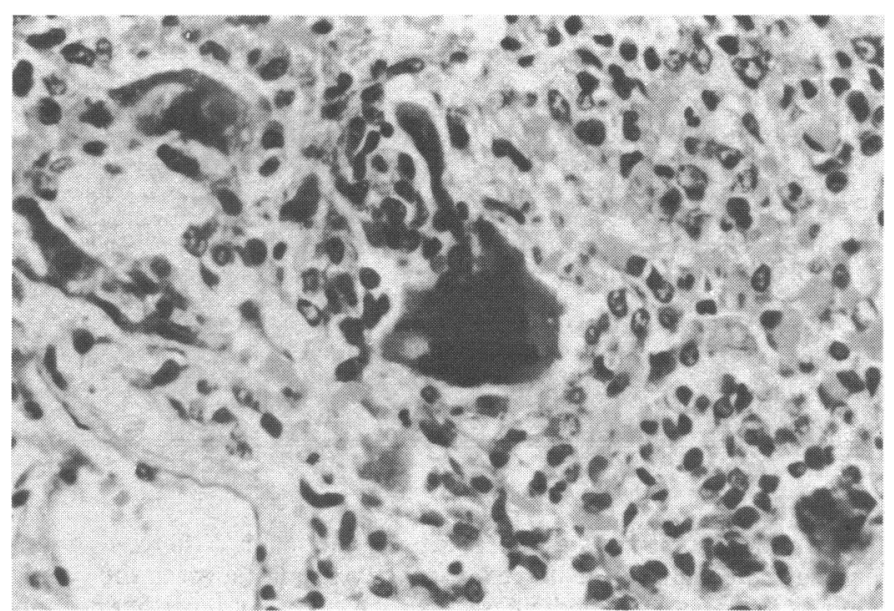

Photomicrograph of lung biopsy specimen showing giant cells and intranuclear inclusion bodies. Haematoxylin and eosin $\times 112$ (original magnification).

\section{Comment}

Interstitial pneumonitis is a major cause of death in children in remission from acute lymphoblastic leukaemia and receiving antineoplastic drugs. Frequent causative organisms include measlesvirus, varicella, cytomegalovirus, and $P$ carinii. Measles may present without the classic rash, as pneumonia or encephalitis. More than one virus may sometimes be present, as reported by Bruce et al, ${ }^{2}$ who isolated $\mathrm{H}$-strain rhinovirus and measlesvirus in such a case. Since $H$ hominis on its own apparently caused only fever or an upper respiratory tract infection, and since herpes carriers are common, the importance of finding this herpesvirus with other viruses was not clear. ${ }^{2}$ None the less, fatal $H$ hominis infection-including pneumonia -is a recognised complication of measles in malnourished children, ${ }^{3}$ in whom immune mechanisms are compromised as they are in children with leukaemia. Furthermore, the histological appearances of the lung in our patient were typical of pneumonia caused by any virus, as well as showing the more specific giant cells characteristic of measles pneumonia. Although the $H$ hominis eventually isolated might have been a contaminant, none of the necropsy team was subsequently found to have active herpes on lips or hands.

That two viruses together may cause a fatal illness is important, since when effective antiviral agents become available possibly they could be combined in the same way as antibacterial "cocktails" for multiple bacterial infections. Already the promising antiherpes agent acyclovir is undergoing clinical trials and might have been useful in this apparently resistant "measles" pneumonia.

We thank Dr S Variend for the photograph and histological review and Dr A W Craft for advice.

${ }^{1}$ Craft AW, Reid MM, Bruce E, Kernahan J, Gardner PS. Role of infection in the death of children with acute lymphoblastic leukaemia. Arch Dis Child 1977;52:752-7.

2 Bruce E, Reid MM, Craft AW, Kernahan J, Gardner PS. Multiple virus isolations in children with acute lymphoblastic leukaemia. fournal of Infection $1979 ; 1: 243-8$.

${ }^{3}$ Becker WB, Kipps A, McKenzie D. Disseminated herpes simplex virus infection. Am $\mathcal{F}$ Dis Child 1968;115:1-8.

(Accepted 8 September 1981)

Departments of Pathology and Haematology, Children's Hospital, Sheffield S10 2TH

JON D BLAND, MRCP, registrar in paediatrics

JOHN S LILLEYMAN, MRCP, MRCPATH, consultant haematologist

\section{Manic psychosis associated with procarbazine}

There has been only one report of mania ${ }^{1}$ associated with procarbazine hydrochloride, which is widely used in Hodgkin's disease ${ }^{2}$; the patient, however, had also received lignocaine and adrenaline. We describe a patient in whom the development, progress, and termination of manic symptoms were linked with procarbazine.

\section{Case report}

A 20-year-old woman bank clerk presented with a four-week history of enlarged cervical nodes, anorexia, weight loss, and pruritus of her legs. Cervical lymph node biopsy and exploratory laparotomy, which showed tumour nodes in the spleen, confirmed the diagnosis of Hodgkin's disease.

Treatment was started on 12 February 1981 with nitrogen mustard, vincristine, procarbazine, and prednisolone. On 10 March the patient was seen by a psychiatrist after her parents complained that she was behaving in a bizarre way, unlike her normally calm, friendly, pleasant, and well-behaved self. They denied any history of drug or alcohol abuse, personal or family history of any psychiatric illness, and cyclothymic mood changes. The patient showed physical overactivity and pressure of speech, constantly shouting, swearing, making erotic suggestions, and talking about spending money. She was emotionally labile but fully conscious and orientated, and there were no signs of a toxic confusional state.

The patient was admitted to hospital and given phenothiazines and lithium carbonate. Computed tomography showed nothing abnormal. Her mood state settled rapidly, and by 20 March she was well enough to start her second course of chemotherapy. This time she was given a single dose of nitrogen mustard, vincristine, and procarbazine but no prednisolone. On 1 April she became hypomanic again as in the first episode despite being continued with lithium carbonate and phenothiazines. Thirteen days later she was quieter, and within a further week she was mentally well.

The patient was subsequently treated with a monthly regimen of bleomycin, 
nitrogen mustard, and vincristine and on 1 June was discharged mentally well. She remained mentally well.

\section{Comment}

The symptoms and absence of organic brain disease in this patient supported a diagnosis of mania. The lack of personal or family history of affective psychosis, the recurrence of symptoms despite lithium carbonate and phenothiazines, and the time relation between the manic episodes and drug treatment suggest that the manic psychosis was unlikely to have been coincidental. Steroids were omitted from the drug regimen preceding the second episode and she was not taking other drugs likely to give psychiatric effects. Psychodynamically a "flight into mania" could be postulated as a reaction to learning about her grave physical illness, but during the episode she felt better than normal and the absence of affective symptoms before and after it makes this unlikely.

Procarbazine hydrochloride (isopropyl- $\alpha-(2-$ methylhydrazine)) is one of the monoamine oxidase inhibitors, long recognised as apt to provoke manic reactions. ${ }^{3}$ Though psychosis is a rare side effect of procarbazine, physicians should be aware of this and of its possible interaction with sympathomimetic agents to produce psychosis. Its antidepressant potential should be further explored.

We thank Dr I Chanarin for advice.

Requests for reprints should be sent to Dr M W P Carney.

Mann AM, Hutchinson JL. Manic reactions associated with procarbazine hydrochloride therapy of Hodgkin's disease. Can Med Assoc $\mathcal{7} 1967$;97 : 1350-3.

2 De Conti RC. Procarbazine in the management of late Hodgkin's disease. fAMA $1971 ; 215: 927-30$.

${ }^{3}$ Schildkraut JJ. A catecholamine hypothesis of affective disorders : a review of supporting evidence. Am F Psychiatry 1965;122:509-22.

(Accepted 16 September 1981)

Northwick Park Hospital and Clinical Research Centre, Harrow Middlesex HA1 3UJ

M W P CARNEY, FRCPI, FRCPSYCH, consultant psychiatrist

A RAVINDRAN, MB, MRCPSYCH, registrar in psychiatry

D S LEWIS, MRCP, MRCPATH, senior registrar in haematology (now at St Mary's Hospital, London W2)

\section{Hypokalaemia induced by a combination of a beta-blocker and a thiazide}

Preparations containing fixed-ratio combinations of a beta-blocker and a thiazide are being used to treat hypertension. The potential for hypokalaemia during such treatment has been understated, and we report a case of profound hypokalaemia induced by Sotazide (sotalol $160 \mathrm{mg}$ and hydrochlorothiazide $25 \mathrm{mg}$ ).

\section{Case report}

A 55-year-old white woman was referred to the London Hospital hypertension clinic for management. She gave a three-year history of essentia hypertension, and 10 weeks before referral Sotazide one tablet twice a day had been prescribed. At presentation she reported serious symptoms including lethargy and dizziness. On examination blood pressure was $150 / 98 \mathrm{~mm} \mathrm{Hg}$ and pulse 64 beats/minute and grade I hypertensive retinopathy was noted. Further examination was normal. Investigation showed normal renal function and plasma potassium concentration of $2.4 \mathrm{mmol}(\mathrm{mEq}) / 1$. Sotazide was withdrawn, and the plasma potassium concentration returned to normal $(3.8 \mathrm{mmol} / \mathrm{l})$ over two weeks.

Triple treatment with propranolol $120 \mathrm{mg}$ twice a day, Moduretic two tablets daily, and hydrallazine $25 \mathrm{mg}$ twice a day was required to control he blood pressure $(134 / 90 \mathrm{~mm} \mathrm{Hg}$ ). Plasma potassium concentration remained normal at $3.5 \mathrm{mmol} / \mathrm{l}$. Sotazide one tablet twice a day was then reintroduced to replace propranolol and Moduretic. Hypokalaemia developed (plasma potassium concentration $3.1 \mathrm{mmol} / 1$ after one week and $2.8 \mathrm{mmol} / 1$ after two weeks) with recurrence of her symptoms. Sotalol $160 \mathrm{mg}$ twice a day was prescribed in place of Sotazide; the plasma potassium concentration returned to normal within one week $(3.8 \mathrm{mmol} / \mathrm{l})$ and she became asymptomatic.

All diuretic treatment was stopped and serum aldosterone concentration estimated, which was within the normal range, thus making unlikely the diagnosis of primary hyperaldosteronism (serum aldosterone concentration $226 \mathrm{pmol} / \mathrm{l}(8 \cdot 1 \mathrm{ng} / 100 \mathrm{ml})$; normal range $150-500 \mathrm{pmol} / \mathrm{l}(5 \cdot 4-1.8 \mathrm{ng} / 100 \mathrm{ml})$.

\section{Comment}

Fixed-ratio combinations of beta-blocker and thiazide diuretics may reduce plasma potassium concentration profoundly, as is well recognised with thiazides alone. ${ }^{1}$ Beta-blockers attenuate the fall in potassium concentration produced by thiazides, ${ }^{2}$ and they raise plasma potassium concentrations by approximately $0.2 \mathrm{mmol} / 1 .^{3} \mathrm{As}$ thiazides cause a mean fall in plasma potassium concentration of about $0.6 \mathrm{mmol} / 1$ the combination of a beta-blocker and a thiazide would be expected to cause a fall of approximately $0.4 \mathrm{mmol} / 1$. Indeed, this has been shown with the combination of sotalol and hydrochlorothiazide. ${ }^{4}$ Therefore, patients prescribed a fixed-ratio combination of a beta-blocker and a diuretic may still develop hypokalaemia and be at risk from its associated complications, which include an increased incidence of ventricular fibrillation and ventricular tachycardia after myocardial infarction ${ }^{5}$ as well as a general increase in non-specific morbidity, particularly in the elderly.

We think, therefore, that serum electrolyte concentrations should be closely monitored in all patients prescribed preparations combining a beta-blocker and a thiazide to avoid these and other consequences of hypokalaemia. Concurrent administration of a potassium-conserving diuretic or adequate potassium supplements may be appropriate.

${ }^{1}$ Morgan DB, Davidson C. Hypokalaemia and diuretics: an analysis of publications. $\mathrm{Br}$ Med $\mathcal{F}$ 1980;280:905-8.

${ }^{2}$ Sweet CS, Gaul SL. Attenuation of hydrochlorthiazide-induced hypokalaemia in dogs by a beta adrenergic blocking drug, Timolol. Eur $\mathcal{f}$ Pharmacol 1975;2:370-4.

${ }^{3}$ Medical Research Council working party on mild to moderate hypertension. Randomised controlled trial of treatment for mild hypertension: design and pilot trial. $\mathrm{Br}$ Med f 1977; i $1437-40$

${ }^{4}$ Jaattela A. The combination of sotalol and hydrochlorthiazide in the treatment of hypertension. $\mathcal{F}$ Clin Pharmacol 1979;19:565-70.

${ }^{5}$ Cole AG, Arkin D, Solomon R. Malignant ventricular dysrhythmias in myocardial infarction: the role of hypokalaemia. International Congress and Symposium series No 44. London: Royal Society of Medicine, $1981: 47-53$.

(Accepted 28 September 1981)

The London Hospital, Whitechapel, London E1 1BB

J D SKEHAN, BSC, MRCP, registrar, medical unit

J N BARNES, MA, MRCP, lecturer, medical unit

P J DREW, MA, MRCP, lecturer, medical unit

$P$ WRIGHT, SRN, sister, hypertension clinic

\section{Retroperitoneal fibrosis associated with metoprolol}

Retroperitoneal fibrosis was first described in 1948. In a few cases an aetiological agent has been identified: analgesic abuse ${ }^{1}$ and methysergide $^{2}$ have been implicated, as more recently have beta-adrenergic blockers including atenolol ${ }^{3}{ }^{4}$ and oxprenolol. ${ }^{5}$ We report a case of retroperitoneal fibrosis in a patient who had been taking metoprolol for 11 months.

\section{Case report}

A 51-year-old labourer was referred to the outpatient clinic in February 1980 because of angina. Blood urea and creatinine concentrations were within the normal range. He had been taking slow-release metoprolol $200 \mathrm{mg}$ daily and nifedipine $10 \mathrm{mg}$ daily since September 1979 . His drug treatmen was altered to thrice-daily metoprolol $50 \mathrm{mg}$, nifedipine $10 \mathrm{mg}$, and isosorbide dinitrate $10 \mathrm{mg}$. In July 1980 he was admitted for coronary angiography and found to have a blood urea concentration of $23.3 \mathrm{mmol} / 1(140 \mathrm{mg} / 100 \mathrm{ml})$ and a creatinine concentration of $729 \mu \mathrm{mol} / 1(8.24 \mathrm{mg} / 100 \mathrm{ml})$. Haemoglobin concentration was $12.8 \mathrm{~g} / \mathrm{dl}$, there was no abnormality on urine microscopy and he was normotensive. Ultrasonography showed dilatation of the pelvicaliceal system in both kidneys; the upper portion of the right ureter appeared normal but the left ureter could not be seen. Cystoscopy showed no abnormality within the bladder, and the ureteric orifices appeared normal. Bilateral Chevassu (retrograde) ureterography disclosed the typical appearances of retroperitoneal fibrosis.

At operation retroperitoneal fibrosis was found affecting the left ureter for a distance of $5 \mathrm{~cm}$ and the right ureter for a distance of $2 \mathrm{~cm}$. Bilateral ureterolysis was performed and the ureters fixed in a lateral position. A Silastic $T$ tube was left as an intubated ureterostomy on the left. Fourteen days after operation his urea concentration was $7.9 \mathrm{mmol} / 1(47.4 \mathrm{mg} / 100 \mathrm{ml})$ and creatinine concentration $155 \mu \mathrm{mol} / 1(1.75 \mathrm{mg} / 100 \mathrm{ml})$. 